\title{
Concurrent palliative chemoradiation leads to survival and quality of life benefits in poor prognosis stage III non-small-cell lung cancer: a randomised trial by the Norwegian Lung Cancer Study Group
}

\author{
H H Strøm*,1,2, R M Bremnes ${ }^{2,3}$, S H Sundstrøm ${ }^{4}, \mathrm{~N} \mathrm{Helbekkmo}^{3}, \varnothing$ Fløtten ${ }^{5}$ and U Aaseb $\varnothing^{2,6}$ \\ ${ }^{1}$ Department of Medicine, Helgeland Hospital, 8800 Sandnessjøen, Norway; ${ }^{2}$ Department of Clinical Medicine, University of Tromsø, \\ N-9037 Tromsø, Norway; ${ }^{3}$ Department Oncology, University Hospital of North Norway, 9038 Tromsø, Norway; \\ ${ }^{4}$ The Cancer Clinic, St. Olavs Hospital, N-7006 Trondheim, Norway; ${ }^{5}$ Department Thoracic Medicine, Haukeland University Hospital, \\ 5021, Bergen, Norway and ${ }^{6}$ Department Pulmonary Medicine, University Hospital of North Norway, 9038 Tromsø, Norway
}

Background: The palliative role of chemoradiation in the treatment of patients with locally advanced, inoperable non-small-cell lung cancer stage III and negative prognostic factors remains unresolved.

Methods: Patients not eligible for curative radiotherapy were randomised to receive either chemoradiation or chemotherapy alone. Four courses of intravenous carboplatin on day 1 and oral vinorelbin on days 1 and 8 were given with 3-week intervals. Patients in the chemoradiation arm also received radiotherapy with fractionation $42 \mathrm{~Gy} / 15$, starting at the second chemotherapy course. The primary end point was overall survival; secondary end points were health-related quality of life (HRQOL) and toxicity.

Results: Enrolment was terminated due to slow accrual after 191 patients from 25 Norwegian hospitals were randomised. Median age was 67 years and $21 \%$ had PS 2. In the chemotherapy versus the chemoradiation arm, the median overall survival was 9.7 and 12.6 months, respectively $(P<0.01)$. One-year survival was $34.0 \%$ and $53.2 \%(P<0.01)$. Following a minor decline during treatment, $\mathrm{HRQOL}$ remained unchanged in the chemoradiation arm. The patients in the chemotherapy arm reported gradual deterioration during the subsequent months. In the chemoradiation arm, there were more hospital admissions related to side effects $(P<0.05)$.

Conclusion: Chemoradiation was superior to chemotherapy alone with respect to survival and HRQL at the expense of more hospital admissions due to toxicity.

Approximately 2800 Norwegians are diagnosed with lung cancer every year (Cancer Registry of Norway, 2011). Due to lack of early symptoms, patients are in general diagnosed at advanced stages, where curative treatment is not possible. For non-small-cell lung cancer (NSCLC), the crucial line between curative and palliative treatment is usually drawn at stage III disease, though depending on clinical prognostic factors.
Twenty years ago, palliative radiotherapy was considered the main treatment for locally advanced NSCLC, yielding effective symptom relief for a limited time, regardless of the dosefractionation regime (Lester et al, 2006). Palliative radiation is still frequently used. Based on a previous Norwegian study, Sundstrom et al reported (Sundstrøm et al, 2004, 2006) that some of the stage III NSCLC patients in the palliative setting benefited from

*Correspondence: Dr HH Strøm; E-mail: hans.henrik.strom@gmail.com

Received 17 April 2013; revised 12 July 2013; accepted 21 July 2013; published online 20 August 2013 
receiving higher-dose thoracic radiotherapy schedules, obtaining long-term survival.

During the last two decades, chemotherapy has been confirmed to prolong survival of advanced NSCLC. Moreover, combinations of chemo- and radiotherapy have been recommended for locally advanced disease (O'Rourke et al, 2010). In theory, the chemotherapy will minimise the risk of distant metastasis and the radiotherapy will preserve loco-regional control (Le Chevalier et al, 1994). A chemotherapeutic drug may, in addition, act as a radio sensitiser and increase the effect of a radiation treatment (Blackstock and Govindan, 2007). Today, the absence of negative clinical prognostic factors, such as poor performance status (PS) and weight loss is considered a prerequisite for achieving the effect of this combined treatment (Crinò et al, 2010). For the patients with negative prognostic factors though, benefit of chemoradiation is presently not documented.

At the time this study was planned, recommended chemotherapy consisted of two-drug platinum-based regimens. The efficacy of carboplatin and vinorelbin is well documented (Helbekkmo et al, 2007; Plessen Von et al, 2008), and the activity of oral vinorelbin is comparable with the intravenous formulation (Jassem et al, 2001; Krzakowski et al, 2008).

For this study, concurrent chemoradiaton was chosen as the treatment modality due to the documented superiority over the sequential approach in locally advanced NSCLC (Fournel et al, 2005). The selected fractionation was 42 Gy/15 fractions, as this is a pragmatic palliative regimen used in Norway. Besides, it is in line with the prolonged survival observed by Sundstrøm et al. (2004) after more protracted palliative radiation schedules.

This phase III trial was carried out to compare a palliative chemoradiation regimen to palliative chemotherapy alone, with respect to survival, health-related quality of life (HRQOL) and toxicity in incurable stage III NSCLC patients with negative prognostic factors.

\section{PATIENTS AND METHODS}

This study was an open, multicenter phase III trial, with a balanced (1:1) randomisation, where patients in both arms received chemotherapy with carboplatin and vinorelbin. The patients in the experimental arm also received radiotherapy between chemotherapy course two and three.

Eligible participants were adults of all ages with locally advanced, unresectable NSCLC stage III with one or more negative prognostic factors (tumour size $\geqslant 8 \mathrm{~cm}$, PS $\geqslant 2$, or weight loss of $>10 \%$ over the last six months). Patients were ineligible if they (1) were candidates for radical radiotherapy, (2) had received previous chemotherapy or (3) had pleural effusion. Patients with WHO performance status of 0-2 were eligible, provided they had adequate haematological, liver and kidney function, and no other active malignant disease (World Health Organization, 1979).

Patients were to stop treatment if the chemotherapy dose was reduced or postponed three times, postponed more than three weeks, or if there were signs of progression during treatment.

The patients were stratified by performance status, age and sex. Written consent and preserved cognitive functions were also mandatory. All patients underwent CT-staging of the thorax and upper abdomen. The Regional Ethical Committee, the Norwegian Social Data Services, and the Norwegian Medicines Agency approved the study. It is registered in ISRCTN (ISRCTN63778716 - Concomitant chemotherapy for treatment of non-small-cell lung cancer - The Conrad study).

Randomisation was performed by phone or fax to the randomisation centre (Clinical Cancer Research Office, University Hospital of North Norway). As the inclusion progressed in a slower rate than expected, the Regional Ethical Committee accepted an extension of the inclusion period. The protocol was amended accordingly.

Therapy. All participants were to receive four courses of chemotherapy in 3-week intervals: Vinorelbin capsules $60 \mathrm{mg} \mathrm{m}^{-2}$ orally on days 1 and 8 and intravenous carboplatin (area under the curve $=5$ (Calvert's formula)) (Calvert et al, 1989) administered for $1 \mathrm{~h}$ on day 1 . Patients $>75$ years of age received $75 \%$ of the estimated full dose. To prevent chemotherapy-induced nausea and vomiting, all patients received premedication with intravenous 5-HT3 antagonists and dexamethasone on day 1 and orally the following two days. On day 8 they received oral 5-HT3 antagonists only.

Before each chemotherapy course, the absolute neutrophil count had to be $>1.0 \times 10^{9} 1^{-1}$ and platelet $>75 \times 10^{9} 1^{-1}$. The doses were reduced by $25 \%$ if absolute neutrophil count was $1.0-1.49 \times 10^{9} 1^{-1}$, platelets were $75-99 \times 10^{9} 1^{-1}$, or preceding nadir absolute neutrophil count was $<0.5 \times 10^{9} 1^{-1}$. Doses were reduced by $50 \%$ if the nadir platelet count was $<50 \times 10^{9} 1^{-1}$, and continued throughout the treatment period. If a treatment course was delayed by more than 21 days, chemotherapy was to be discontinued. If grade 3-4 toxicity or neutropenic infections occurred, chemotherapy was to be postponed until the patients recovered fully, clinically and/or haematologically. Subsequent doses were reduced by $25 \%$. Study treatment was discontinued in cases of disease progression, unacceptable toxicity, or at patient request.

In the chemoradiation arm, radiotherapy was administered as $42 \mathrm{~Gy} / 15$ fractions. This slightly hypofractionated radiation regimen has been used safely in Norway since the 1980s (Kaasa et al, 1988). A decade ago, advanced NSLC patients randomised to $42 \mathrm{~Gy} / 15$ fractions had median survival data at least comparable to the normofractionated regimen ( $50 \mathrm{~Gy} / 25$ fractions) (Sundstrøm et al, 2004). Biologically, $42 \mathrm{~Gy} / 15$ fractions compares to about $50 \mathrm{~Gy}$ in $2 \mathrm{~Gy}$ daily fractions. As the risk of spinal cord myelopathy at $54 \mathrm{~Gy}$, given 2 daily fractions, is only $<1 \%$, this fractionation regimen is considered safe (Kirkpatric et al, 2010). As this regimen was already established, the protocol allowed the treatment planning and dosimetry to be conducted according to the participating institution's standard routines. The radiotherapy was to start simultaneously or shortly after initiation of the second chemotherapy course.

In addition, patients received best supportive care according to individual needs. If patients allocated to the chemotherapy-alone arm were in need of palliative radiotherapy in thorax, a hypofractionated regimen of $17 \mathrm{~Gy} / 2$ fractions (one week apart) was recommended. If skeletal metastases developed, one $8 \mathrm{~Gy}$ fraction was recommended.

Study end points. The main end point was overall survival. Further end points were time to progression, HRQOL, and treatment toxicity.

HRQOL was assessed using the EORTC QLQ-C30 questionnaire version 3.0 and the supplementary questionnaire module LC13, designed specifically for lung cancer and used by the Norwegian Lung Cancer Study Group for more than 10 years (Hjermstad et al, 1998). Toxicity was graded using the Common Terminology Criteria of Adverse Events version 3.0.

Patient follow-up. Blood samples and information about esophagitis were obtained before each chemotherapy course (weeks $0,3,6$, and 9). The HRQOL questionnaires were distributed to the participants at randomisation and at the time of every chemotherapy course, as well as every 8th week after the end of the treatment period, until one year after randomisation. Reminders were mailed if questionnaires were not returned within 14 days. Every study site provided a summary of the radiation and the chemotherapy given 
for each patient, including registered haematological toxicity and esophagitis as well as reasons for any discontinuation of the treatment. During follow-up visits (weeks 12, 20, 28, 36, 44, and 52) PS and possible progression were registered.

Statistical considerations. We aimed to obtain a $15 \%$ change in 1 -year survival, selected HRQOL items, as well as toxicity. On the basis of existing documentation, provided a significance level of $5 \%$ and a statistical power of $80 \%, 350$ patients needed to be included in the study.

Overall survival and time to progression were compared using the Kaplan-Meier method and the Log-rank test, based on intention to treat. The date of death was chosen as the date of progression if no other information was available.

The HRQOL questionnaires were analysed according to the EORTC scoring manuals (Fayers et al, 2001, 2002). Mean scores were calculated from the reported scores. The mean changes were calculated by subtracting the baseline score from the score at each designated time point during and after the treatment for each study arm. The non-parametric Mann-Whitney $U$-test was used for comparing scores. A mean change of $\geqslant 10$ points was considered clinically relevant and significant (Osoba et al, 2005; Brundage et al, 2007).

\section{RESULTS}

Patients. From November 2006 to November 2011, 191 patients from 25 Norwegian hospitals were randomised. Based on our earlier experiences involving monomodality trials, we expected to include the planned 350 patients in three years, that is, 13 patients per month (Plessen Von et al, 2006). Due to slow and declining patient accrual, the Norwegian Lung Cancer Study Group decided to end patient inclusion at five years (November 2011). The planned study size was dimensioned according to an expected $15 \%$ difference in 1-year survival at a significance level of 0.05 and a statistical power of $80 \%$. Given the survival differences between treatment arms, presented below, calculated power estimates for the included 191 patients are $75 \%$ and $97 \%$, respectively for the 1 -year and 2-year survival.

Three patients had to be excluded (Figure 1, Consort diagram (Moher et al, 2010)). Forty patients $(42.6 \%)$ in the chemotherapy arm and thirty-nine patients (41.5\%) in the chemoradiation arm were 70 years or older. Further baseline demographic and clinical characteristics for each treatment arm are summarised in Table 1.

Study therapy. In the treatment arms, $75.5 \%$ (chemotherapy alone) and $77.7 \%$ (chemoradiation) completed all four chemotherapy courses (Figure 1). Eighty-nine percent of patients in the chemoradiation arm completed the radiotherapy. The median start times for the second, third, and fourth chemotherapy course were day 22 , day 44 , and day 68 . In the chemoradiation arm, the median radiation start and termination times were day 24 and day 44, respectively. Five patients did not receive any radiotherapy.

Reasons for discontinuing therapy differed clearly between the treatment arms (Figure 1). In the chemotherapy-alone arm, 14 of the 23 patients stopped chemotherapy prematurely due to disease progression, whereas in the chemoradiation arm 10 of the 23 stopped treatment because of toxicity.

Overall survival and time to progression. Data are presented in Figure 2. The median overall survival was significantly longer in the chemoradiation arm than in the chemotherapy-alone arm with 12.6 and 9.7 months, respectively (Figures 2B, $P<0.001$ ). Furthermore, the 1 - and 2 -year survival rates were $53.2 \%$ vs $34.0 \%(P<0.01)$ and $27.7 \%$ vs $7.4 \%(P<0.01)$, respectively.
Median time to progression (Figure 2A) was 7.0 months in the chemoradiation vs 4.2 months in the chemotherapy arm $(P<0.001)$.

The significant survival benefit of the chemoradiation arm was retained for patients with weight loss $\geqslant 10 \%$ and tumour size $>7 \mathrm{~cm}$ at randomisation. For PS 2 patients, however, overall survival was similar in both treatment arms: 7.5 months in the chemotherapy arm and 7.8 months in the chemoradiation arm $(P=0.24)$. One-year survival was $10.5 \%$ and $28.6 \%$, respectively.

Grade 5 toxicity was similar in the treatment arms. Six patients in the chemotherapy arm died during the treatment period, two following progression during treatment. Four patients in the chemoradiation arm died. Altogether, four patients died from causes not related to their lung cancer (ruptured aortic aneurysm, myocardial infarction, and two from complications following fracture of the femoral neck).

Health-related quality of life. Proportions of completed questionnaires are presented in Figure 3. Of the 188 eligible patients, 186 (99\%) completed the HRQOL questionnaire at randomisation. The median percentages of completed questionnaires the first six months after randomisation were 84.0 in the chemotherapy arm and 85.5 in the chemoradiation arm. The percentage of responders declined in the last six months of the observation period (medians $67.0 \%$ vs $75.0 \%$ ).

The QLQ-C30/LC13 covers several domains. In order to provide an adequate and sufficient HRQOL assessment of the two different treatment regimens in our trial, we have chosen to report global HRQOL, social function, physical functions and dysphagia (Claassens et al, 2011).

Mean scores over time and mean changes from baseline to week 52 are presented in Figure 4, relative to treatment arm. During the treatment period, the patients in the chemoradiation arm recorded a significant temporary worsening in physical and social functioning, as well as dysphagia. However, the values returned to a level near baseline. The patients receiving chemotherapy alone experienced a significant and clinically relevant decline in physical and social function, as well as global HRQOL following the end of the treatment period (Figure 4).

Toxicity. Data on toxicity and side effects are presented in Table 2. During the treatment period, there were significantly more episodes of esophagitis and hospital admissions in the chemoradiation arm (both $P<0.01$ ). More than $85 \%$ of the patients receiving chemoradiation reported various degrees of esophagitis, but none reported grade 4 . The few episodes of esophagitis in the chemotherapy arm were probably related to post study radiation. Neutropenia was somewhat more pronounced $(P=0.258)$ and the number infections was somewhat higher $(P=0.172)$ in the chemoradiation arm. Slightly more patients in the chemoradiation arm required blood transfusion $(P=0.85)$, but there were no differences with respect to bleeding, thrombocytopenia, or number of platelet transfusions given.

Post study treatment. Our data reveal that more patients in the chemotherapy alone than in the chemoradiation arm received supplemental radiation, $58.0 \%$ vs $31.2 \%$, respectively $(P<0.05)$. Correspondingly, $43.7 \%$ in the chemotherapy arm and $24.7 \%$ in the chemoradiation arm received supplemental chemotherapy $(P<0.05)$. Thirteen patients were still alive by 15 January 2013 .

\section{DISCUSSION}

In patients with locally advanced NSCLC stage III and negative prognostic factors, our randomised study demonstrates that concurrent chemoradiation is superior to chemotherapy alone with respect to both survival and HRQOL. The benefit is 


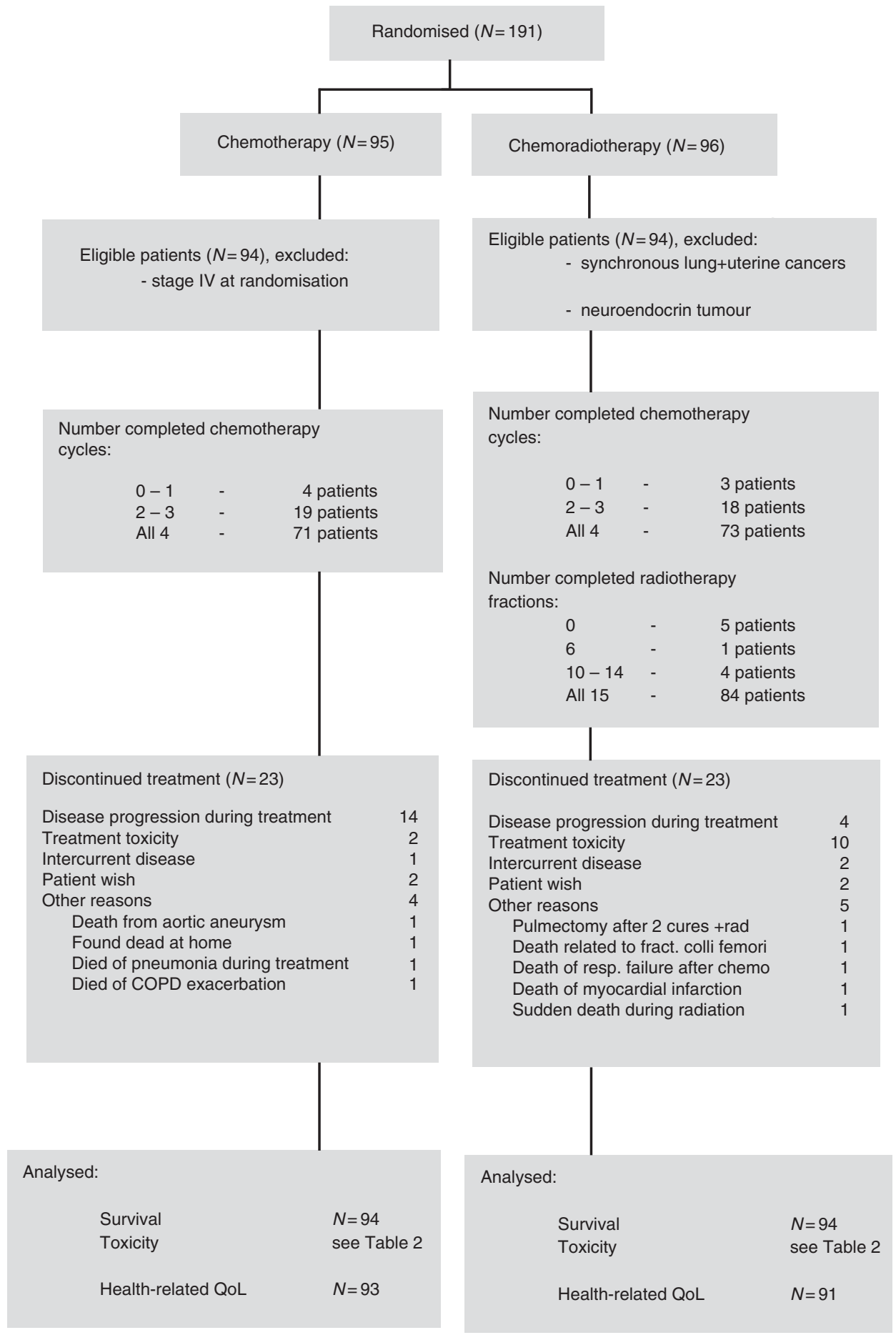

Figure 1. CONSORT flow diagram for the Conrad study.

countered, however, by more hospital admissions due to toxicity.

The role of chemoradiation in palliation of poor-risk patients with incurable stage III NSCLC is not yet settled (Wagner, 2008; Rodrigues et al, 2012). Some investigators have called for more use of radiotherapy in the palliative setting (Barbera and Bezjak, 2013), whereas randomised radiotherapy trials are infrequently including HRQOL end points (Claassens et al, 2011). A major strength of this study is the inclusion of both survival and HRQOL end points. The inability to include the planned number of patients is a weakness. Nevertheless, previous investigators have encountered accrual difficulties, especially with respect to multimodal clinical trials (Baggstrom et al, 2011; Lally et al, 2011). Doctors hesitate to

enrol patients with poor PS and patients cite geographical barriers among reasons for their nonparticipation (Lara et al, 2001). A multimodal treatment trial is an additional challenge in a sparsely populated country like Norway.

To our knowledge, this is the first prospective randomised phase III trial specifically addressing palliative chemoradiation for patients with stage III NSCLC and negative prognostic factors. Our data reveal a significant benefit from palliative chemoradiation compared with chemotherapy alone.

There are few previous chemoradiation studies in poor-risk advanced NSCLC patients. Two phase II studies (Lau et al, 1998; Davies et al, 2006) examined the tolerability and effect of chemoradiation, total radiation dose of $61 \mathrm{~Gy}$ concurrent with 
Table 1. Patients characteristics at baseline

\begin{tabular}{|c|c|c|c|c|c|}
\hline & \multicolumn{2}{|c|}{ Chemotherapy $(\mathbf{N}=94)$} & \multicolumn{2}{|c|}{ Chemoradiotherapy $(\mathbf{N}=94)$} & $\boldsymbol{P}$-value \\
\hline \multicolumn{6}{|l|}{ Age (years) } \\
\hline $\begin{array}{l}\text { Median } \\
\text { Range }\end{array}$ & \multicolumn{2}{|c|}{$\begin{array}{c}66.5 \\
48-88\end{array}$} & \multicolumn{2}{|c|}{$\begin{array}{c}67 \\
48-85\end{array}$} & \\
\hline Sex & & & & & 1.0 \\
\hline $\begin{array}{l}\text { Female } \\
\text { Male } \\
\end{array}$ & \multicolumn{2}{|c|}{$\begin{array}{l}35 \\
59\end{array}$} & \multicolumn{2}{|c|}{$\begin{array}{l}34 \\
60\end{array}$} & \\
\hline & No. patients & $\%$ & No. patients & $\%$ & \\
\hline Performance status & & & & & 0.859 \\
\hline $\begin{array}{l}0-1 \\
2\end{array}$ & $\begin{array}{l}75 \\
19\end{array}$ & $\begin{array}{l}79.8 \\
20.2\end{array}$ & $\begin{array}{l}73 \\
21\end{array}$ & $\begin{array}{l}77.7 \\
22.3\end{array}$ & \\
\hline Stage of disease & & & & & 0.464 \\
\hline $\begin{array}{l}\text { IIIAA } \\
\text { IIIB }\end{array}$ & $\begin{array}{l}46 \\
48\end{array}$ & $\begin{array}{l}49 \\
51\end{array}$ & $\begin{array}{l}40 \\
54\end{array}$ & $\begin{array}{l}43 \\
57\end{array}$ & \\
\hline \multicolumn{6}{|l|}{ Histology } \\
\hline $\begin{array}{l}\text { Squamous cell carcinoma } \\
\text { Adenocarsinoma } \\
\text { Large cell carcinoma } \\
\text { Other }\end{array}$ & $\begin{array}{r}36 \\
31 \\
4 \\
23\end{array}$ & $\begin{array}{r}38.3 \\
33.0 \\
4.3 \\
24.5\end{array}$ & $\begin{array}{r}46 \\
31 \\
1 \\
16\end{array}$ & $\begin{array}{r}48.9 \\
33.0 \\
1.1 \\
17.0\end{array}$ & \\
\hline
\end{tabular}
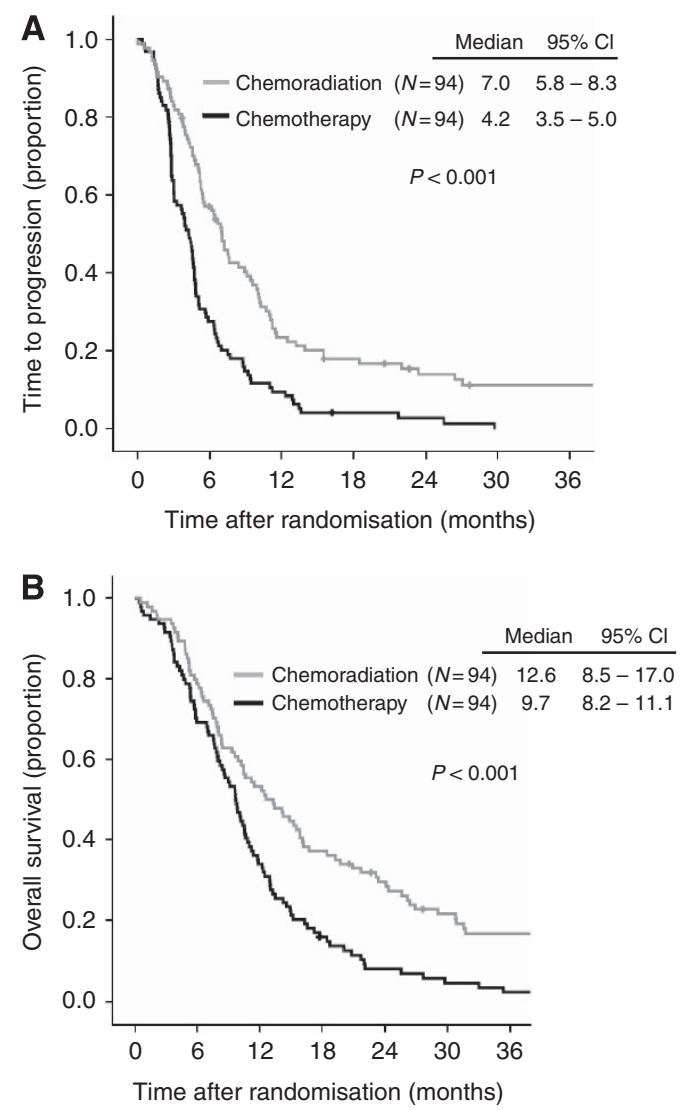

Figure 2. Kaplan-Meier plots for (A) time to progression and (B) overall survival.

carboplatin and etoposid. This regimen was well tolerated and yielded a median survival comparable to that of patients with better prognosis who received cisplatin-based chemoradiotherapy. In a

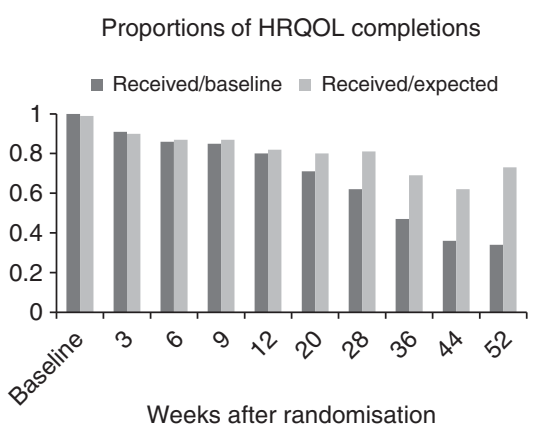

Figure 3. Proportions of health-related quality of life (HRQOL) questionnaires completed at baseline and during the study. The median received/expected proportions were $87.5 \%$ in the first 6 months of the study and $72.3 \%$ for the last 6 months.

recent randomised phase II study, Nawrocki et al (2010) concluded that upfront chemotherapy combined with palliative radiotherapy (30 Gy/10 fractions) resulted in superior response rates and survival when compared with radiotherapy alone in patients with stage III locally advanced NSCLC and poor prognostic factors (tumours $>8 \mathrm{~cm}$ and/or poor pulmonary reserve, performance status $0-2$, tumour-related chest symptoms).

In advanced-stage NSCLC, age has a significant impact on treatment choice and elderly patients are less frequently treated according to guidelines (De Rijke et al, 2004; Blanco et al, 2008). In our study, $42 \%$ of patients were above 70 years and $22 \% \geqslant 75$ years. Nevertheless, higher age was not a poor prognostic factor for survival. This is in agreement with previous studies (Schild et al, 2003; Atagi et al, 2012) on even more aggressive chemoradiation where elderly patients were found eligible as long as they were fit. In our data, only PS was found to be a significant negative prognostic factor for survival. When compared with chemotherapy alone, we conclude that concomitant chemoradiation offers a significant survival benefit to PS 0-1 patients with locally advanced 

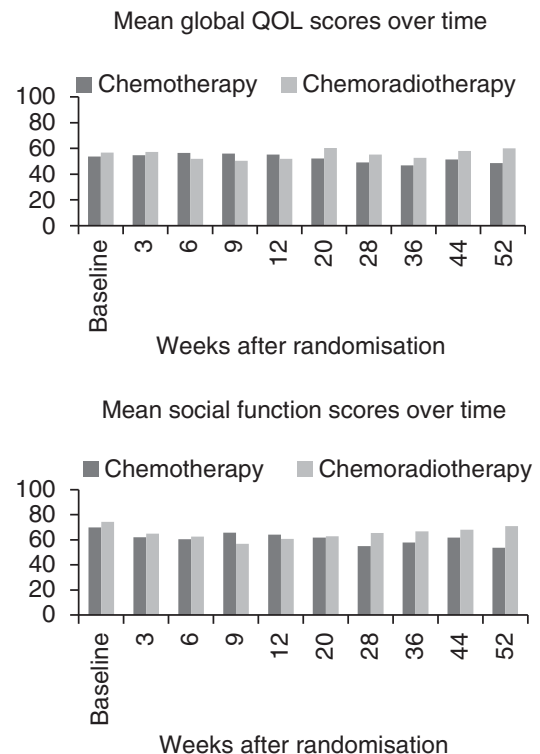

Mean physical function scores over time

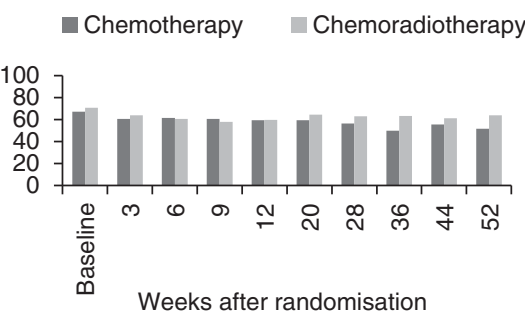

Mean dysphagia scores over time

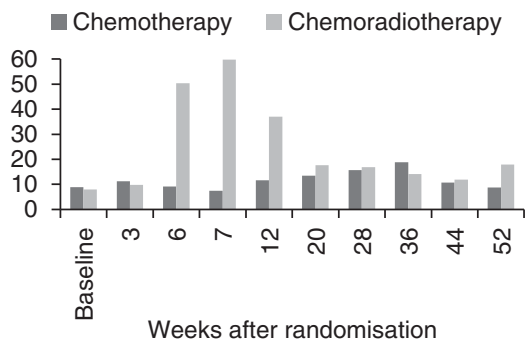

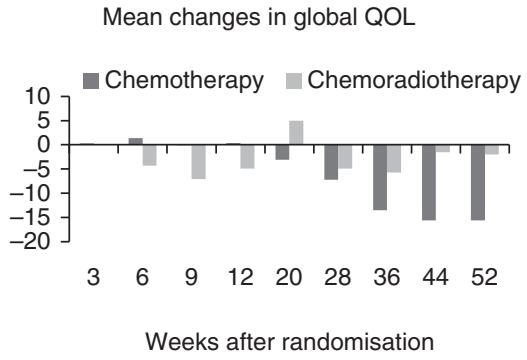

Mean change in social function

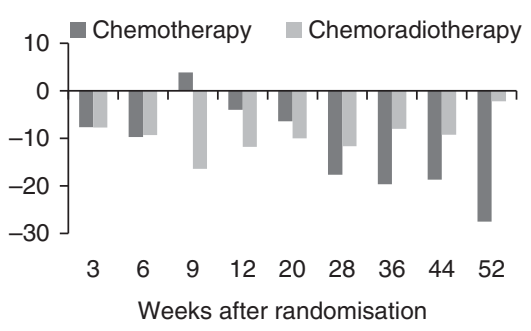

Mean change in physical function

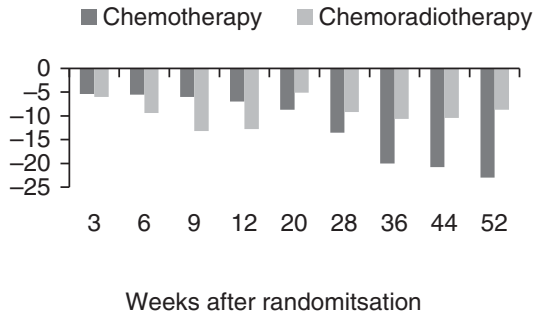

Mean change in dysphagia

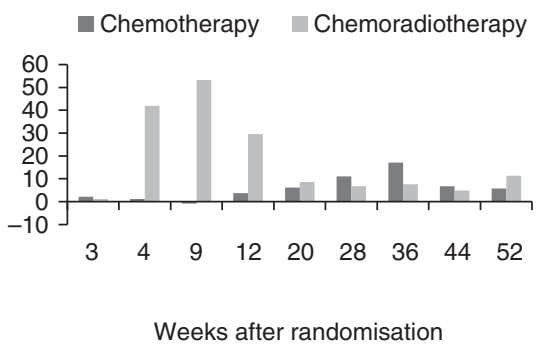

Figure 4. Mean scores and mean change in the selected domains. A higher score for dysphagia indicate more pronounced symptoms, whereas higher score for the three other domains indicate better function.

NSCLC and negative prognostic factors. For PS 2 patients, overall survival was similar in both treatment arms.

During the latter part of the observation period, the compliance with respect to completing questionnaires decreased in parallel with the reported declining quality of life, which is a familiar phenomenon (Fayers et al, 2001). Palliative care patients may find the HRQOL questionnaires too lengthy and some of the items less relevant (Kaasa et al, 1998). At baseline, patients in the chemoradiation arm had a 3.1-4.4 points higher score for the domains reported than those in the chemotherapy-alone arm. First, this difference is considered nonsignificant, and second the interpretation of HRQOL data was based on mean change values (Osoba et al, 1998).

In a longitudinal study of NSCLC patients undergoing concurrent chemoradiation therapy, Wang et al (2006) observed a temporal pattern of treatment effects affecting the patients' symptoms and daily function during and after treatment. Consistently, we found a temporary, reversible decline in HRQOL regarding both symptom and functional domains during therapy, in agreement with others (Pijls-Johannesma et al, 2009).

Despite a transient decrease in global HRQOL due to side effects during the radiation period, the HRQOL decline during this period was limited and clinically insignificant. After the first three months though, a reasonable global HRQOL was maintained in the chemoradiation arm, whereas it declined significantly in the chemotherapy-alone arm. Thus, chemoradiation offers a longer lasting palliation relevant to HRQOL in contrast to chemotherapy alone.

In our study, we used a slightly hypofractionated radiation schedule ( $42 \mathrm{~Gy} / 15$ fractions), and $30 \%$ of the patients in the chemoradiation arm experienced esophagitis grade 3 , but not grade 4. Esophagitis is common in chemoradiation, but the reported incidence rates are conflicting. In patients with locally advanced NSCLC and PS $0-1$ given concurrent chemoradiation, WernerWasik and co-workers (RTOG) (Werner-Wasik et al, 2011) reported $75 \%$ esophagitis grade $3-4$ and $34 \%$ grade 4 following standard $(63 \mathrm{~Gy})$ or hyperfractionated radiation therapy 


\begin{tabular}{|c|c|c|c|c|c|}
\hline & \multicolumn{2}{|c|}{$\begin{array}{l}\text { Carboplatin/ } \\
\text { vinorelbin }\end{array}$} & \multicolumn{2}{|c|}{$\begin{array}{c}\text { Carboplatin/vinorelbin }+ \text { concurrent } \\
\text { radiation }\end{array}$} & \multirow[b]{2}{*}{$P$-value } \\
\hline & No. patients & $\%$ & No. Patients & $\%$ & \\
\hline Haematologic toxicity (183 valid cases) & $(N=91)$ & & $(N=92)$ & & \\
\hline Anaemia & & & & & 0.514 \\
\hline Grade 3 & 5 & 5.5 & 5 & 5.4 & \\
\hline Grade 4 & 0 & 0 & 0 & 0 & \\
\hline Neutropenia & & & & & 0.258 \\
\hline Grade 3 & 21 & 23.1 & 18 & 19.6 & \\
\hline Grade 4 & 14 & 15.4 & 23 & 25.0 & \\
\hline Thrombocytopenia & & & & & 0.094 \\
\hline Grade 3 & 3 & 3.3 & 6 & 6.5 & \\
\hline Grade 4 & 1 & 1.1 & 3 & 3.3 & \\
\hline No. infections in relation to leukopenia (170 valid cases) & $(N=86)$ & & $(N=84)$ & & 0.172 \\
\hline 1 & 16 & 18.6 & 23 & 27.4 & \\
\hline 2 & 1 & 1.2 & 4 & 4.8 & \\
\hline 3 & 1 & 1.2 & 0 & 0 & \\
\hline No. hospital admissions in relation to side effects ( 170 valid cases) & $(N=86)$ & & $(N=84)$ & & $<0.01$ \\
\hline 1 & 18 & 20.9 & 33 & 39.7 & \\
\hline 2 & 4 & 4.7 & 9 & 10.7 & \\
\hline 3 & 1 & 1.2 & 3 & 3.6 & \\
\hline Esophagitis in relation to radiation (156 valid cases) & $(N=67)$ & & $(N=90)$ & & $<0.01$ \\
\hline Grade 0 & 58 & 86.6 & 12 & 13.3 & \\
\hline Grade 1 & 4 & 6.0 & 16 & 17.8 & \\
\hline Grade 2 & 4 & 6.0 & 35 & 38.9 & \\
\hline Grade 3 & 1 & 1.5 & 27 & 30.0 & \\
\hline Grade 4 & 0 & 0 & 0 & 0 & \\
\hline
\end{tabular}

(69.6 Gy). In two Japanese studies (Takigawa et al, 2011; Atagi et al, 2012) on elderly patients with good PS, given concurrent curative chemoradiation ( $60 \mathrm{~Gy}$ ), only $1-6 \%$ were reported to have grade 3-4 esophagitis. A high percentage of our poor-risk patient population completed the planned courses of chemotherapy and radiotherapy, but a relatively large proportion of patients in the chemoradiation arm suffered from esophagitis and infections related to leucopenia.

The haematological toxicities were comparable to other studies (Helbekkmo et al, 2007; Gronberg et al, 2009; Takigawa et al, 2011), but the number of hospital admissions in relation to side effects was relatively large (45 in the chemoradiation vs 23 in the chemotherapy arm). One patient in the chemoradiation arm died during radiation (after 11 fractions). The cause of death was arrhythmia.

In conclusion, we found that concurrent chemoradiation is superior to chemotherapy alone in poor prognosis patients with locally advanced stage III with respect to both survival and HRQOL. Higher age and large tumour size were not negative prognostic factors. PS 2 patients had no survival benefit and should receive chemotherapy alone. Future trials to establish the best concurrent chemoradiotherapy regimen (radiation dose/fractionation, volume, planning, and new systemic therapies) are required to provide further information regarding the optimal treatment for this challenging patient population. Herein, HRQOL should be a study end point in addition to survival.

\section{ACKNOWLEDGEMENTS}

This research was supported by unrestricted grants from the North Norway Regional Health Authority and Pierre Fabre.

\section{REFERENCES}

Atagi S, Kawahara M, Yokoyama A, Okamoto H, Yamamot N, Ohe Y, Sawa T, Ishikura S, Shibata T, Fukuda H (2012) Thoracic radiotherapy with or without daily low-dose carboplatin in elderly patients with non-small-cell lung cancer: a randomised, controlled, phase 3 trial by the Japan Clinical Oncology Group (JCOG0301). Lancet Oncol 13: 671-678.

Baggstrom MQ, Waqar SN, Sezhiyan AK, Gilstrap E, Gao F, Morgensztern D, Govindan R (2011) Barriers to enrollment in non-small cell lung cancer therapeutic clinical trials. J Thorac Oncol 6: 98-102.

Barbera L, Bezjak A (2013) Have we forgotten that radiation is an effective therapy for lung cancer? J Thorac Oncol 8: 4-5.

Blackstock AW, Govindan R (2007) Definitive chemoradiation for the treatment of locally advanced non small-cell lung cancer. J Clin Oncol 25: $4146-4152$.

Blanco JAG, Toste IS, Alvarez RF, Cuadrado GR, Gonzalvez AM, Martín IJG (2008) Age, comorbidity, treatment decision and prognosis in lung cancer. Age Ageing 37: 715-718.

Brundage M, Osoba D, Bezjak A, Tu D, Palmer M, Pater J. National Cancer Institute of Canada Clinical Trials Group (2007) Lessons learned in the assessment of health-related quality of life: selected examples from the 
National Cancer Institute of Canada Clinical Trials Group. J Clin Oncol 25: 5078-5081.

Calvert AH, Newell DR, Gumbrell LA, O’Reilly S, Burnell M, Boxall FE, Siddik ZH, Judson IR, Gore ME, Wiltshaw E (1989) Carboplatin dosage: prospective evaluation of a simple formula based on renal function. J Clin Oncol 7: 1748-1756.

Cancer Registry of Norway (2011) Cancer in Norway 2009. Special issue: Cancer Screening in Norway, In: Haldorsen T (eds). Cancer Registry of Norway: Oslo.

Claassens L, van Meerbeeck J, Coens C, Quinten C, Ghislain I, Sloan EK, Wang XS, Velikova G, Bottomley A (2011) Health-related quality of life in non-small-cell lung cancer: an update of a systematic review on methodologic issues in randomized controlled trials. J Clin Oncol 29: 2104-2120.

Crinò L, Weder W, van Meerbeeck J, Felip E. ESMO Guidelines Working Group (2010) Early stage and locally advanced (non-metastatic) nonsmall-cell lung cancer: ESMO Clinical Practice Guidelines for diagnosis, treatment and follow-up. Ann Oncol 21(Suppl 5): v103-v115.

Davies AM, Chansky K, Lau DHM, Leigh BR, Gaspar LE, Weiss GR, Wozniak AJ, Crowley JJ, Gandara DR. SWOG S9712 (2006) Phase II study of consolidation paclitaxel after concurrent chemoradiation in poor-risk stage III non-small-cell lung cancer: SWOG S9712. J Clin Oncol 24: $5242-5246$

De Rijke JM, Schouten LJ, ten Velde GPM, Wanders SL, Bollen ECM, Lalisang RI, Van Dijck JAAM, Kramer GWP, Van Den Brandt PA (2004) Influence of age, comorbidity and performance status on the choice of treatment for patients with non-small cell lung cancer; results of a population-based study. Lung Cancer 46: 233-245.

Fayers P, Aaronson N, Bjordal K, Groenvold M, Curran D, Bottomley A. on behalf of the EORTC QOL Group. (2001) The EORTC QLQ-C30 scoring manual (ed 3). European Organisation for Research and Treatment of Cancer: Brussels, Belgium.

Fayers P, Bottomley A. EORTC Quality of Life Group, Quality of Life Unit (2002) Quality of life research within the EORTC-the EORTC QLQ-C30. European Organisation for Research and Treatment of Cancer. Eur J Cancer 38(Suppl 4): S125-S133.

Fournel P, Robinet G, Thomas P, Souquet P-J, Léna H, Vergnenégre A, Delhoume J-Y, Le Treut J, Silvani J-A, Dansin E, Bozonnat M-C, Daurés J-P, Mornex F, Pérol M. Groupe Lyon-Saint-Etienne d'Oncologie Thoracique-Groupe Français de Pneumo-Cancérologie (2005) Randomized phase III trial of sequential chemoradiotherapy compared with concurrent chemoradiotherapy in locally advanced non-small-cell lung cancer: Groupe Lyon-Saint-Etienne d'Oncologie Thoracique-Groupe Français de Pneumo-Cancérologie NPC 95-01 Study. J Clin Oncol 23: 5910-5917.

Gronberg BH, Bremnes RM, Flotten O, Amundsen T, Brunsvig PF, Hjelde HH, Kaasa S, Plessen Von C, Stornes F, Tollali T, Wammer F, Aasebo U, Sundstrom S (2009) Phase iii study by the Norwegian lung cancer study group: pemetrexed plus carboplatin compared with gemcitabine plus carboplatin as first-line chemotherapy in advanced non-small-cell lung cancer. J Clin Oncol 27: 3217-3224.

Helbekkmo N, Sundstrøm SH, Aasebo U, Brunsvig PF, Plessen Von C, Hjelde HH, Garpestad OK, Bailey A, Bremnes RM. Norwegian Lung Cancer Study Group (2007) Vinorelbin/carboplatin vs gemcitabine/ carboplatin in advanced NSCLC shows similar efficacy, but different impact of toxicity. $\mathrm{Br} J$ Cancer 97: 283-289.

Hjermstad MJ, Fayers PM, Bjordal K, Kaasa S (1998) Health-related quality of life in the general Norwegian population assessed by the European Organization for Research and Treatment of Cancer Core Quality-of-Life Questionnaire: the QLQ = C30 (+3). J Clin Oncol 16: 1188-1196.

Jassem J, Ramlau R, Karnicka-Młodkowska H, Krawczyk K, Krzakowski M, Zatloukal P, Lemarie E, Hartmann W, Novakova L, O'Brien M, Depierr A (2001) A multicenter randomized phase II study of oral vs. intravenous vinorelbin in advanced non-small-cell lung cancer patients. Ann Oncol 12: 1375-1381.

Kaasa S, Hjermstad MJ, Jordhøy MS, Wisløff F, Loge JH (1998) Compliance in quality of life data: a Norwegian experience. Stat Med 17: 623-632.

Kaasa S, Thorud E, Høst H, Lien HH, Lund E, Sjølie I (1988) A randomized study evaluating radiotherapy versus chemotherapy in patients with inoperable non-small cell lung cancer. Radiother Oncol 11: 7-13.

Kirkpatrick JP, van der Kogel AJ, Schultheiss TE (2010) Radiation dosevolume effects in the spinal cord. Int J Radiat Oncol Biol Phys 76: S42-S49.
Krzakowski M, Provencio M, Utracka-Hutka B, Villa E, Codes M, Kuten A, Henke M, Lopez M, Bell D, Biti G, Merimsky O, Beorchia A, Riggi M, Caux N-R, Pouget J-C, Dubray B, David P (2008) Oral vinorelbin and cisplatin as induction chemotherapy and concomitant chemoradiotherapy in stage III non-small cell lung cancer: final results of an international phase II trial. J Thorac Oncol 3: 994-1002.

Lally BE, Wagner H, Langer C, Thomas CR (2011) Assessing patient accrual to cooperative group lung cancer trials: why are rates disappointing? J Thorac Oncol 6: 1971-1973.

Lara PN, Higdon R, Lim N, Kwan K, Tanaka M, Lau DH, Wun T, Welborn J, Meyers FJ, Christensen S, O’Donnell R, Richman C, Scudder SA, Tuscano J, Gandara DR, Lam KS (2001) Prospective evaluation of cancer clinical trial accrual patterns: identifying potential barriers to enrollment. J Clin Oncol 19: 1728-1733.

Lau DH, Crowley JJ, Gandara DR, Hazuka MB, Albain KS, Leigh B, Fletcher WS, Lanier KS, Keiser WL, Livingston RB (1998) Southwest Oncology Group phase II trial of concurrent carboplatin, etoposid, and radiation for poor-risk stage III non-small-cell lung cancer. J Clin Oncol 16: $3078-3081$.

Le Chevalier T, Arriagada R, Quoix E, Ruffie P, Martin M, Douillard JY, Tarayre M, Lacombe-Terrier MJ, Laplanche A (1994) Radiotherapy alone versus combined chemotherapy and radiotherapy in unresectable non-small cell lung carcinoma. Lung Cancer 10(Suppl 1): S239-S244.

Lester JF, Macbeth FR, Toy E, Coles B (2006) Palliative radiotherapy regimens for non-small cell lung cancer. Cochrane Database Syst Rev (4): doi:10.1002/14651858.CD002143.pub2.

Moher D, Hopewell S, Schulz KF, Montori V, Gøtzsche PC, Devereaux PJ, Elbourne D, Egger M, Altman DG. Consolidated Standards of Reporting Trials Group (2010) CONSORT 2010 Explanation and elaboration: updated guidelines for reporting parallel group randomised trials. J Clin Epidemiol 63: e1-e37.

Nawrocki S, Krzakowski M, Wasilewska-Tesluk E, Kowalski D, Rucinska M, Dziadziuszko R, Sowa A (2010) Concurrent chemotherapy and short course radiotherapy in patients with stage IIIA to IIIB non-small cell lung cancer not eligible for radical treatment: results of a randomized phase II study. J Thorac Oncol 5: 1255-1262.

O’Rourke N, Roqué I, Figuls M, Farré Bernadó N, Macbeth F (2010) Concurrent chemoradiotherapy in non-small cell lung cancer. Cochrane Database Syst Rev (6): doi:10.1002/14651858.CD002140.pub3.

Osoba D, Bezjak A, Brundage M, Zee B, Tu D, Pater J. Quality of Life Committee of the NCIC CTG (2005) Analysis and interpretation of health-related quality-of-life data from clinical trials: basic approach of The National Cancer Institute of Canada Clinical Trials Group. Eur J Cancer 41: 280-287.

Osoba D, Rodrigues G, Myles J, ZEE B, PATER J (1998) Interpreting the significance of changes in health-related quality-of-life scores. J Clin Oncol 16: $139-144$.

Pijls-Johannesma M, Houben R, Boersma L, Grutters J, Seghers K, Lambin P, Wanders R, De Ruysscher D (2009) High-dose radiotherapy or concurrent chemo-radiation in lung cancer patients only induces a temporary, reversible decline in QoL. Radiother Oncol 91: 443-448.

Plessen Von C, Bergman B, Andresen O, Bremnes RM, Sundstrom S, Gilleryd M, Stephens R, Vilsvik J, Aasebo U, Sorenson S (2006) Palliative chemotherapy beyond three courses conveys no survival or consistent quality-of-life benefits in advanced non-small-cell lung cancer. Br J Cancer 95: 966-973.

Plessen Von C, Strand T-E, Wentzel-Larsen T, Omenaas E, Wilking N, Sundstrom S, Sorenson S (2008) Effectiveness of third-generation chemotherapy on the survival of patients with advanced non-small cell lung cancer in Norway: a national study. Thorax 63: 866-871.

Rodrigues G, Macbeth F, Burmeister B, Kelly K-L, Bezjak A, Langer C, Hahn C, Movsas B (2012) Consensus statement on palliative lung radiotherapy: third international consensus workshop on palliative radiotherapy and symptom control. Clin Lung Cancer 13: 1-5.

Schild SE, Stella PJ, Geyer SM, Bonner JA, McGinnis WL, Mailliard JA, Brindle J, Jatoi A, Jett JR. North Central Cancer Treatment Group (2003) The outcome of combined-modality therapy for stage III non-small-cell lung cancer in the elderly. J Clin Oncol 21: 3201-3206.

Sundstrøm S, Bremnes R, Aasebø U, Aamdal S, Hatlevoll R, Brunsvig P, Johannessen DC, Klepp O, Fayers PM, Kaasa S (2004) Hypofractionated palliative radiotherapy (17 gy per two fractions) in advanced non-small-cell lung carcinoma is comparable to standard fractionation 
for symptom control and survival: a national phase III trial. J Clin Oncol 22: 801-810.

Sundstrøm S, Bremnes RM, Brunsvig P, Aasebø U, Kaasa S, Norwegian Lung Cancer Study Group (2006) Palliative thoracic radiotherapy in locally advanced non-small cell lung cancer: can quality-of-life assessments help in selection of patients for short- or long-course radiotherapy? J Thorac Oncol 1: 816-824.

Takigawa N, Kiura K, Segawa Y, Hotta K, Tamaoki A, Tokuda Y, Nagata T, Watanabe K, Gemba K, Moritaka T, Horita N, Takeda H, Okimoto N, Takemoto M, Matsuo K, Shinkai T, Tabata M, Ueoka H, Kanazawa S, Tanimoto M (2011) Benefits and adverse events among elderly patients receiving concurrent chemoradiotherapy for locally advanced non-small cell lung cancer: analysis of the Okayama Lung Cancer Study Group trial 0007. J Thorac Oncol 6: 1087-1091.

Wagner H (2008) Just enough palliation: radiation dose and outcome in patients with non-small-cell lung cancer. J Clin Oncol 26: 3920-3922.
Wang XS, Fairclough DL, Liao Z, KOMAKI R, Chang JY, Mobley GM, Cleeland CS (2006) Longitudinal study of the relationship between chemoradiation therapy for non-small-cell lung cancer and patient symptoms. J Clin Oncol 24: 4485-4491.

Werner-Wasik M, Paulus R, Curran WJ, Byhardt R (2011) Acute esophagitis and late lung toxicity in concurrent chemoradiotherapy trials in patients with locally advanced non-small-cell lung cancer: analysis of the radiation therapy oncology group (RTOG) database. Clin Lung Cancer 12: 245-251.

World Health Organization (1979) WHO Handbook for Reporting Results of Cancer Treatment. WHO offset publication No. 48WHO: Geneva, Switzerland.

(c) (1) (2) (2) This work is licensed under the Creative Commons (c) ${ }_{\text {BY }}$ NC SA Attribution-NonCommercial-Share Alike 3.0 Unported License. To view a copy of this license, visit http://creativecommons. org/licenses/by-nc-sa/3.0/ 